Research Article

\title{
Type I Fracture Toughness Test of Rock-like Materials Based on the Particle Flow Method
}

\author{
Ling Yue, ${ }^{1}$ Bangyong Yu $\mathbb{C D}^{1},{ }^{1}$ Chengxi Zhao, ${ }^{1}$ Fei Guo, ${ }^{2,3}$ and Fei Huang ${ }^{4}$ \\ ${ }^{1}$ Institute of Construction Engineering, Changzhou Vocational Institute of Engineering, Changzhou 213164, Jiangsu, China \\ ${ }^{2}$ Ministry of Education Key Laboratory of Geological Disaster of Three Gorges Reservoir Area, China Three Gorges University, \\ Yichang 443002, Hubei, China \\ ${ }^{3}$ National Field Observation and Research Station of Landslides, Three Gorges Reservoir Area of Yangtze River, \\ China Three Gorges University, Yichang 443002, China \\ ${ }^{4}$ China Design Group Co., Ltd., Nanjing 210014, Jiangsu, China
}

Correspondence should be addressed to Bangyong Yu; yby_cumt@126.com

Received 25 June 2020; Revised 4 August 2020; Accepted 23 August 2020; Published 18 September 2020

Academic Editor: Zhiqiang Yin

Copyright (c) 2020 Ling Yue et al. This is an open access article distributed under the Creative Commons Attribution License, which permits unrestricted use, distribution, and reproduction in any medium, provided the original work is properly cited.

In order to investigate the feasibility and reliability of the three-dimensional particle flow method in simulating the type I fracture toughness test, four types of numerical samples were established by particle flow code $\mathrm{PFC}^{3 \mathrm{D}}$ : straight crack three-point bending (SC3PB), edge cracked flattened semicircular disc (ECFSD), cracked chevron notched Brazilian disc (CCNBD), and edge cracked flattened ring (ECFR). Three models with different strength parameters (group A, group B, and group C) were established for each type, in which group A parameters are obtained from the concrete model, group B parameters are applied for simulating marble, and group $\mathrm{C}$ parameters are for granite. The type I fracture toughness and the failure form of each model are obtained by conducting the numerical test, and the curves of load versus displacement of loading point are recorded. The numerical test results show that, with the same strength parameter, the maximum difference in test results of each specimen type is $0.39 \mathrm{MPa} \cdot \mathrm{m}^{1 / 2}$. The $K_{\text {IC }}$ of ECFR specimen is $0.13-0.28 \mathrm{MPa} \cdot \mathrm{m}^{1 / 2}$ smaller than that of CCNBD specimen, and the $K_{\mathrm{IC}}$ of ECFSD specimen is slightly higher than that of CCNBD sample. The $K_{\mathrm{IC}}$ of SC3PB specimen is $0.06-0.21 \mathrm{MPa} \cdot \mathrm{m}^{1 / 2}$ smaller than that of the CCNBD sample. When the loading rate is less than $0.01 \mathrm{~m} / \mathrm{s}$, the effect of loading rate on fracture toughness can be reduced to less than $0.1 \mathrm{MPa} \cdot \mathrm{m}^{1 / 2}$.

\section{Introduction}

The research of theoretical and laboratory test for type I fracture toughness $\mathrm{K}_{\mathrm{IC}}$ of rock materials is relatively mature [1]. Typical test methods include three-point bending test, compact tensile test, and Brazilian splitting test, and the specimen types of SC3PB, CCNBD, and SR are commonly used.

Zhang et al. [2] found that the fracture toughness of the sample without notch is higher, and the discreteness in results is obtained. Cui et al. [3] reviewed the testing methods of type I fracture toughness of rocks, compared the results by different methods, and explained the causes of these differences. Wei et al. [4] think that the results of three-point bending test are more stable and reliable, and it is recommended to use the formula proposed by ASTM. Ayatollahi et al. [5] found that the larger the diameter specimen, the higher the type I fracture toughness. The research results of Meng et al. [6] and Yang et al. [7] show that as the center angle of the platform Brazil sample increases, the failure mode becomes complex. The most appropriate platform angle is $20^{\circ}$. Huang et al. $[8,9]$ study the influence of different particle sizes on load-displacement curves and failure modes by $\mathrm{PFC}^{2 \mathrm{D}}$. The results show that the generation of secondary cracks is mainly affected by particle sizes. The size effect in particle flow software simulation has been studied by Wong et al. [10]. It was found that the increase of particle size would cause the increment in fracture toughness and crack initiation stress. The deformation characteristics of sandstone and granite are 
researched under different stress path by Peng et al. [11-14], Wang et al. [15], and Shang et al. [16], and the energy characteristics during crack propagation are studied. It is found that the most sensitive parameter for stage identification is the volumetric strain. With the increment of confining pressure, the development and connection direction of cracks are inhibited, and the length of the final fracture surface decreases. The test process and results of SR and CCNBD specimens are studied by Cui et al. $[17,18]$. The results suggest significant size effects of CCNBD specimens. As the specimen diameters increase, the variance in fracture toughness $K_{\mathrm{IC}}$ of $\mathrm{SR}$ and CCNBD specimen becomes smaller. The facture surface of SR specimen is rougher than that of CCNBD. It is also found that fracture toughness test results can be more consistent by the specimen with larger diameter than the ISRM suggested "minimum effective diameter $75 \mathrm{~mm}$." Based on the boundary effect theory, the fracture toughness of rock is studied by Guan et al. [19]. The real material parameters without size effect of different rock types are constructed, and the results are used to predict the fracture trend.

Experimental study on the fracture toughness of CCNBD specimen and the size effect was conducted by Wu et al. It is proposed that the results can be modified by geometric shape function, and then the real fracture toughness of rock can be obtained. In semicircular bending (SCB) test, the support type influence on rock fracture toughness is researched by Bahrami et al. [20]. The results of finite element method and laboratory tests show that different support types and the friction between the specimen and the bottom supports have great influence on results. The fracture toughness $K_{\text {IC }}$ of lapilli-ash tuff is researched by Wong et al. [21] with two typical semicircular bending specimens. The fracture toughness $K_{\mathrm{IC}}$ measured by semicircular bending (SCB) method is found to be lower than that using cracked chevron notched semicircular bending (CCNSCB) method. The CCNBD method produces more scattered results.

In laboratory tests of rock fracture toughness $K_{\mathrm{IC}}$, the sample processing is relatively difficult, and the test results are scattered. Therefore, numerical simulation method is widely used to test rock fracture toughness. Most of the numerical tests are simulated by two-dimensional software, and three-dimensional numerical calculation method has not been widely discussed. In this study, four types of sample are selected, and three-dimensional particle flow numerical simulation is used to test the type I fracture toughness of the samples. The results are compared and analyzed, which provides a reference for numerical test of fracture toughness.

\section{Establishing a Numerical Model}

2.1. Microparameters of the Model. Particle flow software PFC is widely used to simulate the deformation and failure process of elastic-plastic materials, such as rock, soil, and concrete, which can show the mechanical properties and failure mechanism from a micro perspective. By adjusting the parameters of particle and bond model, the mechanical characteristics of numerical model can be similar to actual materials. Failure process can be obtained by monitoring the number and location of microcracks and the stress in model. In order to study the applicability of numerical simulation in rock materials with different strength, three groups of micro parameters (group A, B, and C) are selected for calculation and analysis (see Tables 1-3), among which the strength parameters are lowest in group A and highest in group C.

The parameters in group A are calibrated according to the results of direct shear test in the laboratory. The parameters in group $\mathrm{B}$ are the micro parameters for marble taken by Huang et al. [22]. The parameters of group $\mathrm{C}$ are modified based on the Brazil split test curve for granite. The uniaxial compressive strength of numerical models can be used to calibrate parameters, and the test results show that the strength is $78.4 \mathrm{MPa}$ with group A parameters, 106.8 $\mathrm{MPa}$ with group B parameters, and $142.1 \mathrm{MPa}$ with group $\mathrm{C}$ parameters.

As $\mathrm{PFC}^{2 \mathrm{D}}$ is used in reference [17], the rationality of micro parameters in three-dimensional particle flow simulation needs to be further tested and modified. The details of parameter calibration in group A are as follows:

(1) Mix cement, sand, and water evenly by the mass ratio of $1: 1: 0.4$, put them into a cubic mold sized $15 \mathrm{~cm} \times 15 \mathrm{~cm} \times 15 \mathrm{~cm}$ (as shown in Figure 1), and vibrate them tightly. After placing for 1 day, demold them and cure them at room temperature for 28 days; then, a similar model sample can be obtained [23], whose physical and mechanical properties are close to actual rock.

(2) Carry out uniaxial compress test and direct shear test on samples under different normal stress (as shown in Figure 2); then, normal stress and shear stress during the test are recorded and plotted in Figure 3. The test results show that the cohesion $c$ of the sample is $5.09 \mathrm{MPa}$, and the internal friction angle $\varphi$ is $44.8^{\circ}$ (as shown in Figure 3 ). The uniaxial compressive strength of samples is $82.3 \mathrm{MPa}$.

(3) Establish PFC $^{3 \mathrm{D}}$ numerical models of the same size, and carry out numerical test with the micro parameters of Huang et al. [13]. Modify these parameters until the test results are closer to those of the laboratory test; then, plot the results in Figure 3. The test results show that the cohesion $c$ of the sample is $4.93 \mathrm{MPa}$ and the internal friction angle $\varphi$ is $46.7^{\circ}$ (as shown in Figure 3 ); take the micro parameters as group $\mathrm{A}$.

The calibration and modification of parameters in group $\mathrm{C}$ are as follows:

(1) Cylindrical specimens sized $\phi 50 \mathrm{~mm} \times 25 \mathrm{~mm}$ are made with intact granite; then, a series of Brazil disk split tests and uniaxial compress tests are conducted with these specimens (as shown in Figure 4). The load-displacement curves of the test are recorded in Figure 5. According to the procedures, during the Brazil tests, the loading rate is controlled as $0.1 \mathrm{MPa} /$ s. The uniaxial compress strength of granite samples is $142.3 \mathrm{MPa}$. 
TABle 1: Particles microscopic parameters of group A.

\begin{tabular}{|c|c|c|c|c|c|c|c|c|c|}
\hline \multicolumn{5}{|c|}{ Particle parameters } & \multicolumn{5}{|c|}{ Parallel bond parameters } \\
\hline $\begin{array}{l}\text { Density } \\
\left(\mathrm{kg} \times \mathrm{m}^{-3}\right)\end{array}$ & $\begin{array}{l}\text { Ratio of } \\
\text { particle } \\
\text { size }\end{array}$ & $\begin{array}{l}\text { Contact } \\
\text { modulus } \\
(\mathrm{GPa})\end{array}$ & $\begin{array}{l}\text { Contact } \\
\text { stiffness } \\
\left(k_{\mathrm{n}} \times k_{\mathrm{s}}^{-1}\right)\end{array}$ & $\begin{array}{l}\text { Friction } \\
\text { coefficient }\end{array}$ & $\begin{array}{l}\text { Bond } \\
\text { modulus } \\
(\mathrm{GPa})\end{array}$ & $\begin{array}{c}\text { Ratio of bond } \\
\text { stiffness } \\
\left(p b \_k_{\mathrm{n}} \times p b \_k_{\mathrm{s}}^{-1}\right)\end{array}$ & $\begin{array}{l}\text { Normal } \\
\text { bond } \\
\text { strength } \\
(\mathrm{GPa})\end{array}$ & $\begin{array}{l}\text { Shear bond } \\
\text { strength } \\
(\mathrm{MPa})\end{array}$ & $\begin{array}{l}\text { Multiplier } \\
\text { of radius }\end{array}$ \\
\hline 1850 & 1.6 & 2.3 & 2.0 & 0.45 & 2.3 & 2.0 & 11 & 15 & 1.0 \\
\hline
\end{tabular}

TABle 2: Particles microscopic parameters of group B.

\begin{tabular}{|c|c|c|c|c|c|c|c|c|c|}
\hline \multicolumn{5}{|c|}{ Particle parameters } & \multicolumn{5}{|c|}{ Parallel bond parameters } \\
\hline $\begin{array}{l}\text { Density } \\
\left(\mathrm{kg} \times \mathrm{m}^{-3}\right)\end{array}$ & $\begin{array}{l}\text { Ratio of } \\
\text { particle } \\
\text { size }\end{array}$ & $\begin{array}{c}\text { Contact } \\
\text { modulus } \\
(\mathrm{GPa})\end{array}$ & $\begin{array}{c}\text { Contact } \\
\text { stiffness } \\
\left(k_{\mathrm{n}} \times k_{\mathrm{s}}^{-1}\right)\end{array}$ & $\begin{array}{l}\text { Friction } \\
\text { coefficient }\end{array}$ & $\begin{array}{l}\text { Bond } \\
\text { modulus } \\
(\mathrm{GPa})\end{array}$ & $\begin{array}{c}\text { Ratio of bond } \\
\text { stiffness } \\
\left(p b \_k_{\mathrm{n}} \times p b \_k_{\mathrm{s}}^{-1}\right)\end{array}$ & $\begin{array}{l}\text { Normal } \\
\text { bond } \\
\text { strength } \\
(\mathrm{MPa})\end{array}$ & $\begin{array}{l}\text { Shear bond } \\
\text { strength } \\
(\mathrm{MPa})\end{array}$ & $\begin{array}{c}\text { Multiplier } \\
\text { of radius }\end{array}$ \\
\hline 2700 & 1.66 & 55 & 2.2 & 0.5 & 55 & 2.2 & 80 & 80 & 1.0 \\
\hline
\end{tabular}

TABLE 3: Particles microscopic parameters of group C.

\begin{tabular}{|c|c|c|c|c|c|c|c|c|c|}
\hline \multicolumn{5}{|c|}{ Particle parameters } & \multicolumn{5}{|c|}{ Parallel bond parameters } \\
\hline $\begin{array}{l}\text { Density } \\
\left(\mathrm{kg} \times \mathrm{m}^{-3}\right)\end{array}$ & $\begin{array}{l}\text { Ratio of } \\
\text { particle } \\
\text { size }\end{array}$ & $\begin{array}{c}\text { Contact } \\
\text { modulus } \\
(\mathrm{GPa})\end{array}$ & $\begin{array}{l}\text { Contact } \\
\text { stiffness } \\
\left(k_{\mathrm{n}} \times k_{\mathrm{s}}^{-1)}\right.\end{array}$ & $\begin{array}{l}\text { Friction } \\
\text { coefficient }\end{array}$ & $\begin{array}{l}\text { Bond } \\
\text { modulus } \\
(\mathrm{GPa})\end{array}$ & $\begin{array}{c}\text { Ratio of bond } \\
\text { stiffness } \\
\left(p b \_k_{\mathrm{n}} \times p b \_k_{\mathrm{s}}^{-1}\right)\end{array}$ & $\begin{array}{l}\text { Normal } \\
\text { bond } \\
\text { strength } \\
(\mathrm{MPa})\end{array}$ & $\begin{array}{l}\text { Shear bond } \\
\text { strength } \\
(\mathrm{MPa})\end{array}$ & $\begin{array}{l}\text { Multiplier } \\
\text { of radius }\end{array}$ \\
\hline 2800 & 1.66 & 5.0 & 3.0 & 0.8 & 35 & 3.0 & 70 & 140 & 1.0 \\
\hline
\end{tabular}

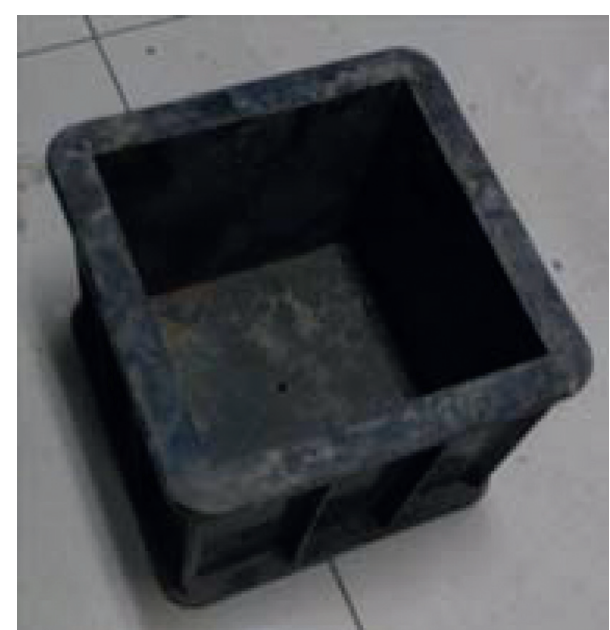

Figure 1: Similar model sample mold.

(2) Establish the numerical model of particle flow and carry out the numerical test according to step (1), and then adjust the micro parameters of the model repeatedly, until the load-displacement curves of numerical test agree well with those of laboratory tests (as shown in Figure 5). The parameters are taken as group C.

Based on the above micro parameters, 12 numerical models of SC3PB, ECFSD, CCNBD, and ECFR were established, respectively, among which SC3PB and CCNBD

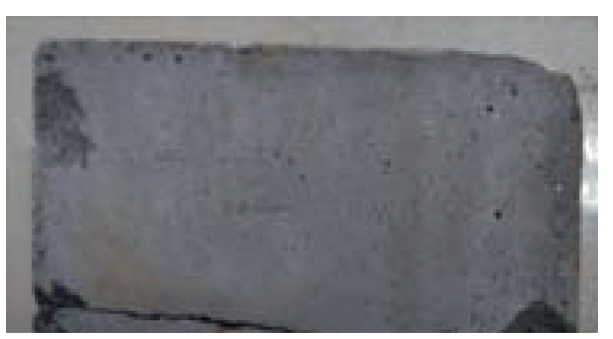

Figure 2: Direct shear test of similar model sample.

models have been widely used, and ECFSD and ECFR are new type models studied by Zhang [24]. The size and loading form of models are shown in Figures 6-9. According to Potyondy et al. [25], the particle size can be selected as 3-4\% of the model size, and numerical tests are carried out for each model.

2.2. Controlling the Loading Rate. Displacement loading is used in the test. In order to select an optimal loading rate, the SC3PB and CCNBD sample models are established with parameters in group $\mathrm{A}$, and the test is executed under three loading rates of $0.05 \mathrm{~m} / \mathrm{s}$ [9], $0.01 \mathrm{~m} / \mathrm{s}$, and $0.002 \mathrm{~m} / \mathrm{s}$ [26]. The strength curves of the two samples under different loading rates are obtained, respectively (as shown in Figures 10 and 11).

Elastic stages of the curves, under different loading rates, are almost the same. The slower the loading rate, the lower the peak strength of the curve. For SC3PB sample, $K_{\mathrm{IC}}$ is 


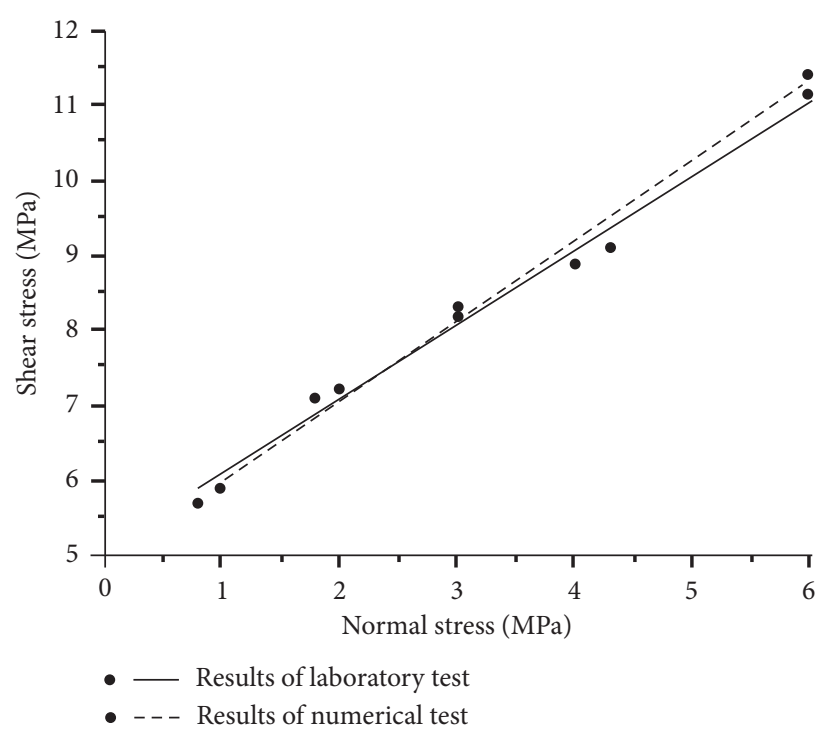

FIGURE 3: Shear stress-normal stress curve of sample.
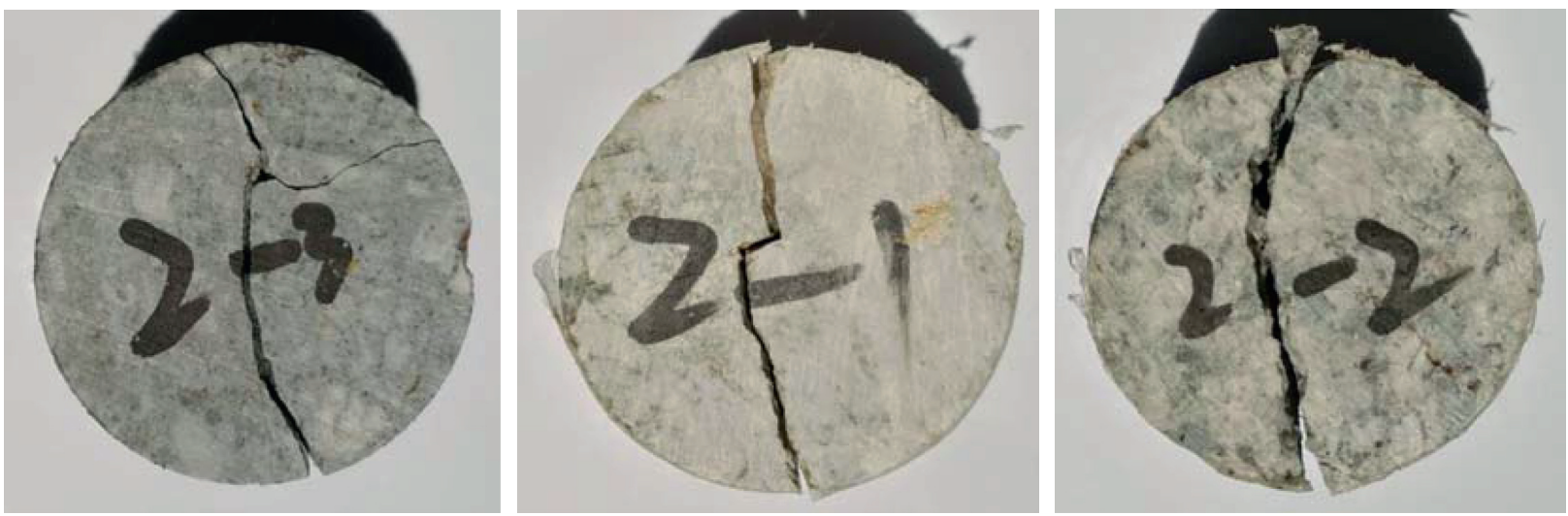

FIGURE 4: Brazil disk split test with granite specimens.

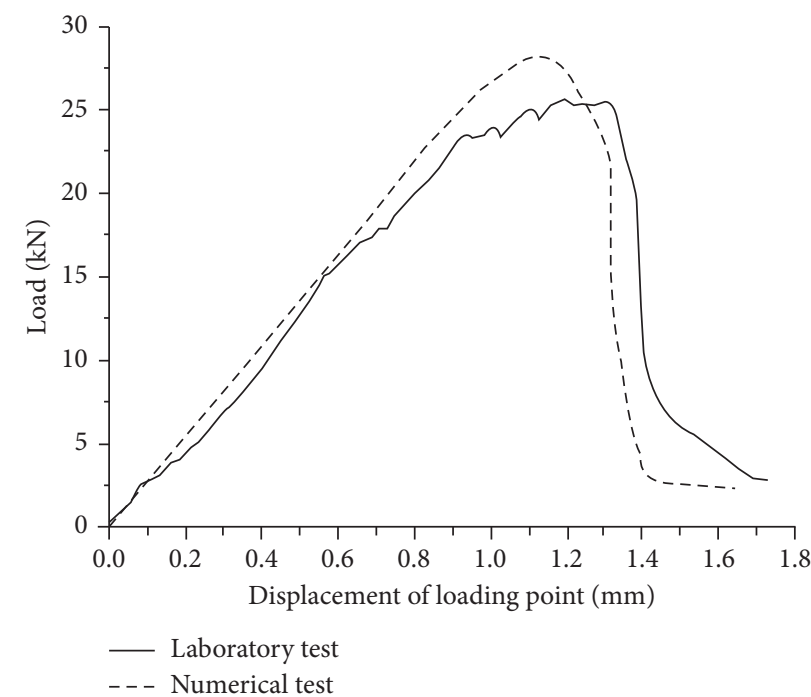

FIgURE 5: Load-displacement curve of Brazil test (parameter of group C). 


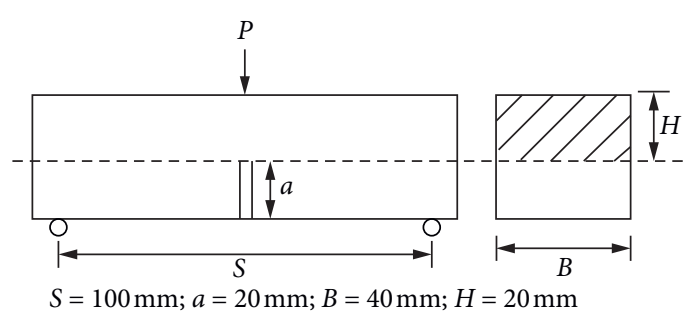

(a)

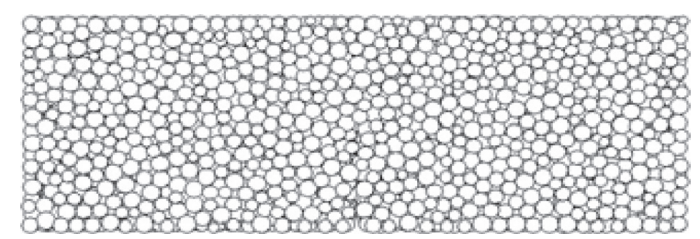

(b)

FIgure 6: Three-point bending beam model. (a) Model size. (b) PFC $^{3 \mathrm{D}}$ model.

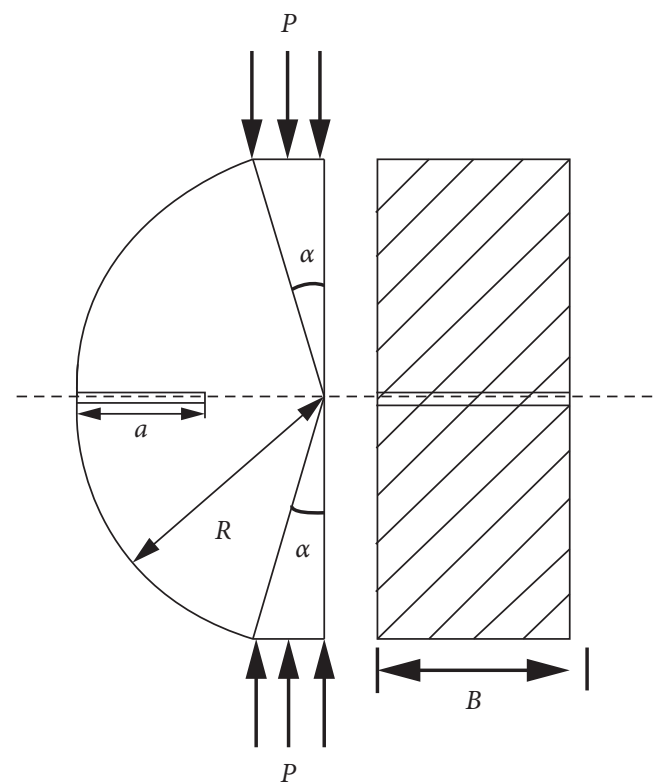

$R=40 \mathrm{~mm} ; a=20 \mathrm{~mm} ; a=10^{\circ} ; B=30 \mathrm{~mm}$

(a)

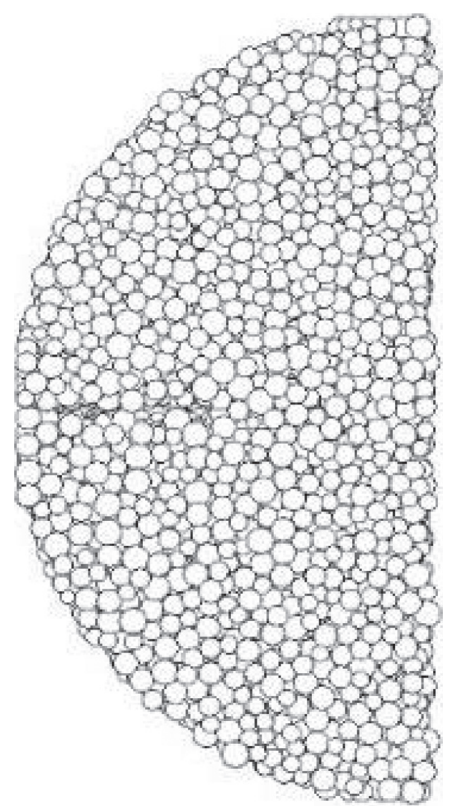

(b)

Figure 7: Edge cracked flattened semicircular disc model. (a) Model size. (b) PFC $^{3 \mathrm{D}}$ model.

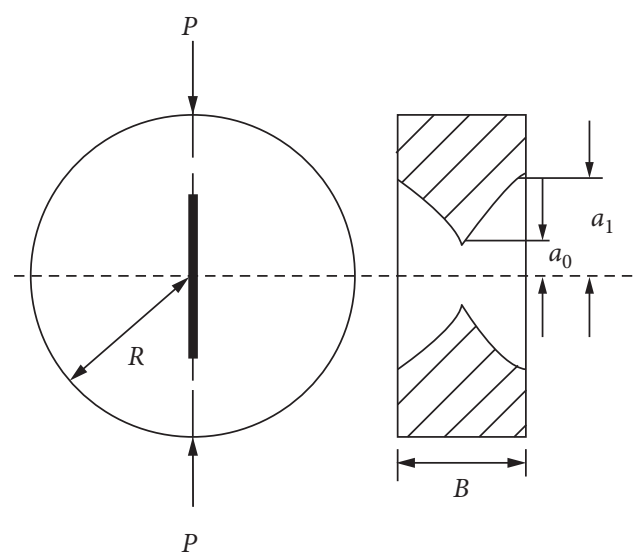

$R=40 \mathrm{~mm} ; a_{0}=7.4 \mathrm{~mm} ; a_{1}=20 \mathrm{~mm} ; B=30 \mathrm{~mm}$

(a)

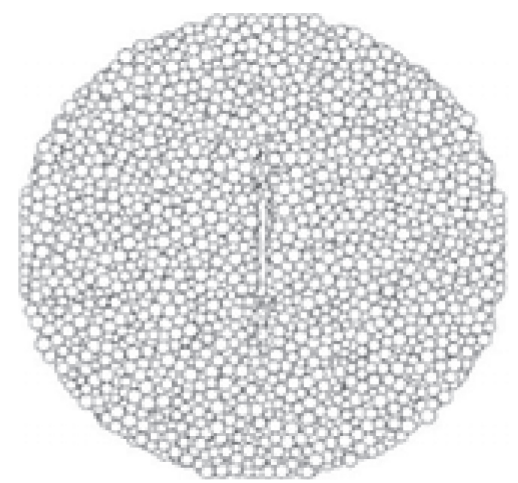

(b)

FIgure 8: Cracked chevron notched Brazilian disc model. (a) Model size. (b) PFC $^{3 \mathrm{D}}$ model. 


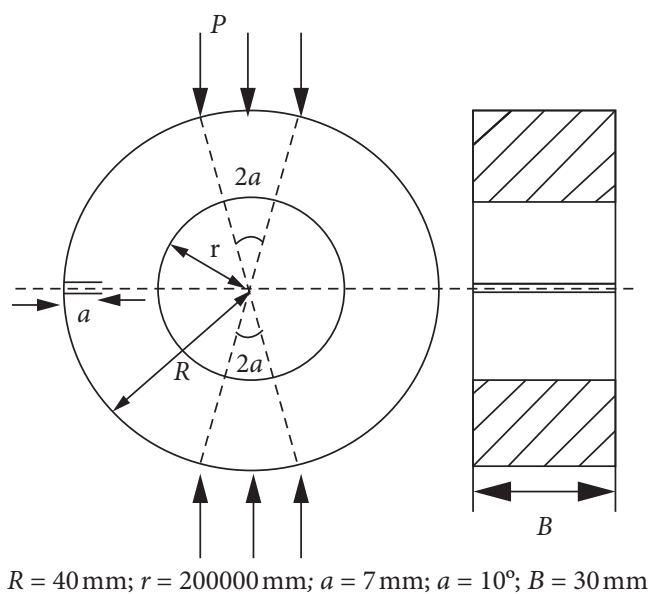

(a)

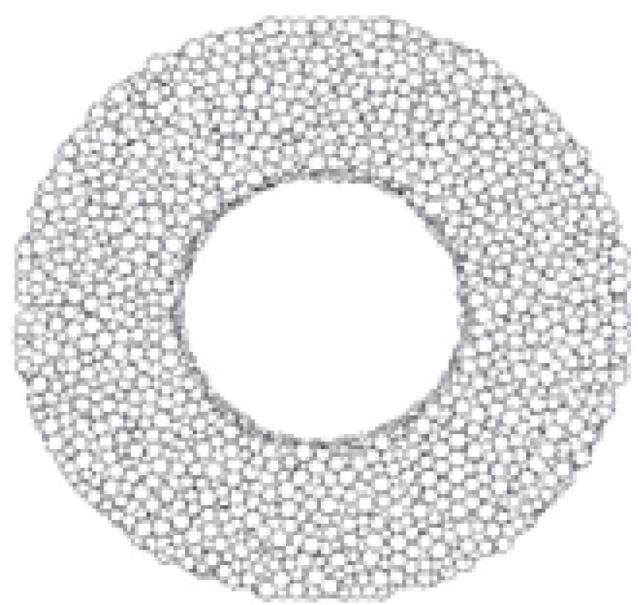

(b)

FIgURE 9: Edge cracked flattened ring model. (a) Model size. (b) $\mathrm{PFC}^{3 \mathrm{D}}$ model.

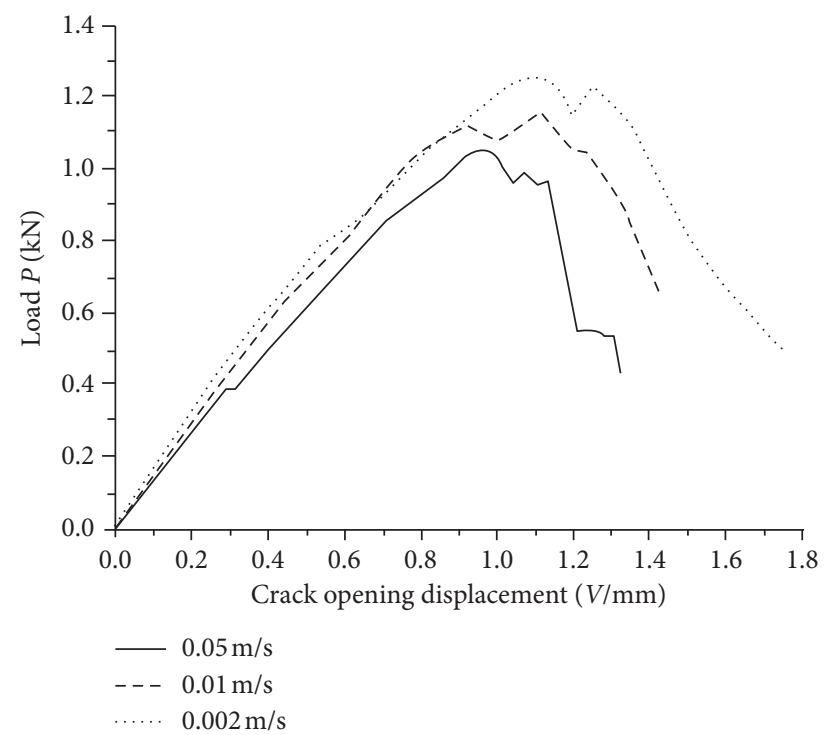

Figure 10: $P-V$ curve of the three-point bending test under different loading rates.

calculated by substituting the first load platform in the curve into formulas (1) and (2) [27]:

$$
\begin{aligned}
K_{\mathrm{IC}}= & \frac{\mathrm{PS}}{\mathrm{BW}^{3 / 2}} f\left(\frac{a}{W}\right), \\
f\left(\frac{a}{W}\right)= & \frac{3(a / W)^{1 / 2}}{2(1+2 a / W)(1-a / W)^{3 / 2}}[1.99-(a / W) \\
& \left.\cdot(1-a / W)\left(2.15-3.93 a / W+2.7 a^{2} / W^{2}\right)\right],
\end{aligned}
$$

where $P$ is the load value, $\mathrm{kN} ; s$ is the nominal span, $\mathrm{mm} ; W$ is the specimen height, $\mathrm{mm} ; B$ is the specimen thickness, $\mathrm{mm}$; and $a$ is the prefabricated crack length, $\mathrm{mm}$.

For CCNBD samples, $K_{\mathrm{IC}}$ is calculated by substituting the maximum load [5] in test by formulas (3)-(6) [28]:

$$
\begin{aligned}
K_{\mathrm{IC}}= & Y_{\min }^{*} \frac{P_{\max }}{\sqrt{2 R B}}, \\
Y_{\min }^{*}= & u e^{v \alpha_{1}}, \\
u\left(\alpha_{0}, \alpha_{\mathrm{B}}\right)= & 0.2553+0.0925 \alpha_{\mathrm{B}}+0.0327 \alpha_{0}+0.1929 \alpha_{0}^{2} \\
& +0.3473 \alpha_{0}^{3}-0.9695 \alpha_{0}^{4}, \\
v\left(\alpha_{0}, \alpha_{\mathrm{B}}\right)= & 2.4404-0.8582 \alpha_{0}-1.2698 \alpha_{\mathrm{B}}+0.469 \alpha_{0} \alpha_{\mathrm{B}} \\
& +0.7345 \alpha_{0}^{2}+0.4819 \alpha_{\mathrm{B}}^{2},
\end{aligned}
$$

where $Y_{\min }^{*}$ is critical strength factor; $\alpha_{0}=a_{0} / R$, the dimensionless initial crack length; $\alpha_{1}=a_{1} / R$, the dimensionless maximum crack length; $\alpha_{\mathrm{B}}=a_{\mathrm{B}} / R$, the dimensionless specimen thickness; and $P_{\max }$, the local maximum load, $\mathrm{kN}$. 


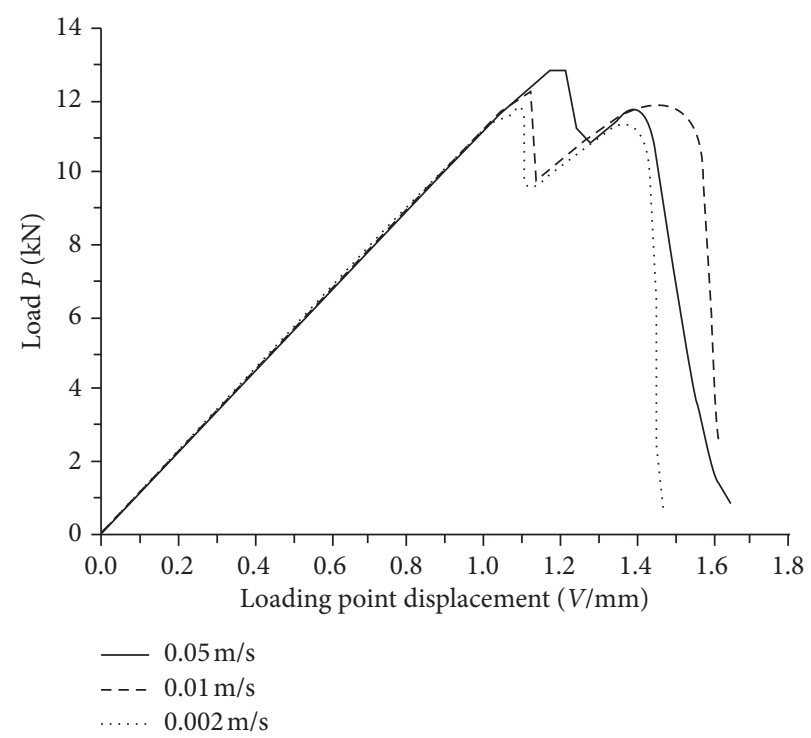

Figure 11: $P-v$ curve of the CCNBD test under different loading rates.

The fracture toughness of the samples under various loading rates is listed in Table 4 . The results of SC3PB samples, with the error of $0.16 \mathrm{MPa} \cdot \mathrm{m}^{1 / 2}$, are greatly affected by loading rate. The results of CCNBD samples are almost close to the error of $0.08 \mathrm{MPa} \cdot \mathrm{m}^{1 / 2}$. With the decrease of loading rate, the influence of loading rate becomes smaller. The slower the loading rate is, the closer the test is to the quasi-static loading. With the same displacement, there is less damage in the sample, and the results are more accurate. Therefore, theoretically, the loading rate should be controlled relatively low, but considering the calculation efficiency of numerical simulation, the loading rate should be increased properly under the condition that the results are accurate enough. According to the above test, the loading rate of this test is controlled as $0.01 \mathrm{~m} / \mathrm{s}$.

\section{Results of the Numerical Test}

3.1. Three-Point Bending Test Results. For numerical test, first of all, the rationality and validity of the test results should be preliminarily judged. Through monitoring the generation and distribution of microcracks in the model, the failure form of the sample can be observed (as shown in Figures 12-14. The black part in the figure represents the microcracks produced by the bond failure between particles. Among them, Figures 12(a), 13(a), and 14(a) show the crack initiation, Figures 12(b), 13(b), and 14(b) show the crack propagation, and Figures 12(c), 13(c), and 14(c) show that the specimen is damaged when the crack propagates to a certain stage. It is found that, in the samples with different strength, the microcracks are first generated from the tip of the preformed groove and gradually expand, indicating that the failure of the model is caused by the growth of the groove, so the numerical test is reasonable and effective.

Then, record the curve of load $P$-crack opening displacement $V$ in the test (as shown in Figure 15). According to the test results, $P_{\mathrm{A}}=1.11 \mathrm{kN}, P_{\mathrm{B}}=2.99 \mathrm{kN}, P_{\mathrm{C}}=3.27 \mathrm{kN}$; substituting these values into formula (1), the $K_{\mathrm{IC}}$ of model A1 is calculated as $0.92 \mathrm{MPa} \cdot \mathrm{m}^{1 / 2}, K_{\mathrm{IC}}$ of model $\mathrm{B} 1$ is $2.49 \mathrm{MPa} \cdot \mathrm{m}^{1 / 2}$, and $K_{\mathrm{IC}}$ of model $\mathrm{C} 1$ is $2.72 \mathrm{MPa} \cdot \mathrm{m}^{1 / 2}$.

3.2. ECFSD Test Results. During the test, the distribution of microcracks in the model is shown in Figures 16-18. It is found that a small number of microcracks, at the crack initiation stage, appear at the loading point and the prefabricated crack end. Then, the prefabricated crack propagation stops after about $5 \mathrm{~mm}$, and a large number of microcracks appear at the two loading points. Crushing along the loading direction is the main failure mode of the sample.

In B2 model, the crack occurs at the loading points firstly and then occurs at the end of precrack (as shown in Figure 17). The fracture in the direction of diameter caused by stress concentration at both ends of the specimen is the main cause of specimen failure.

Record the curve of load $P$-displacement $V$ in the test (as shown in Figure 19), and substitute the local minimum value on the curve into the following formula [19]:

$$
K_{\mathrm{IC}}=Y_{\max } \frac{P_{\min }}{\sqrt{R B}},
$$

where $Y_{\max }$ is the dimensionless stress intensity factor [17], $Y_{\max }=1.0756 ; R$ is the radius of sample, $\mathrm{mm} ; P_{\min }$ is the local minimum load, $\mathrm{kN}$; and the other symbols are the same as before.

According to the test results, $P_{\text {Amin }}=6.22 \mathrm{kN}$, $P_{\mathrm{Bmin}}=14.9 \mathrm{kN}, P_{\mathrm{Cmin}}=16.3 \mathrm{kN}$; then, $K_{\mathrm{IC}}$ of models can be calculated. The results show that $K_{\mathrm{IC}}=1.11 \mathrm{MPa} \cdot \mathrm{m}^{1 / 2}$ for A2 model, $K_{\mathrm{IC}}=2.66 \mathrm{MPa} \cdot \mathrm{m}^{1 / 2}$ for B2 model, and $K_{\mathrm{IC}}=2.91 \mathrm{MPa} \cdot \mathrm{m}^{1 / 2}$ for $\mathrm{C} 2$ model. The observation of the loading process shows that the local minimum value $P_{\min }$ of the load curve corresponds to the crack initiation and 
TABLE 4: Test results of fracture toughness under different loading rates.

\begin{tabular}{lccc}
\hline Loading rate & $0.05 \mathrm{~m} / \mathrm{s}$ & $0.01 \mathrm{~m} / \mathrm{s}$ & $0.002 \mathrm{~m} / \mathrm{s}$ \\
\hline SC3PB & 1.04 & 0.92 & 0.88 \\
CCNBD & 1.19 & 1.13 & 1.11 \\
\hline
\end{tabular}

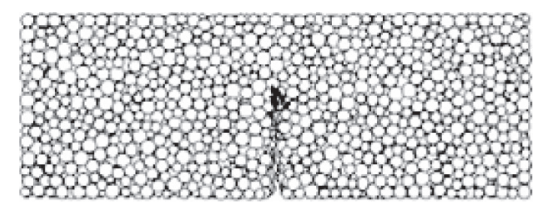

(a)

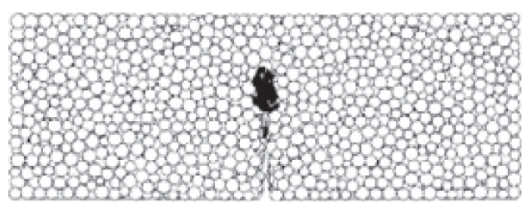

(b)

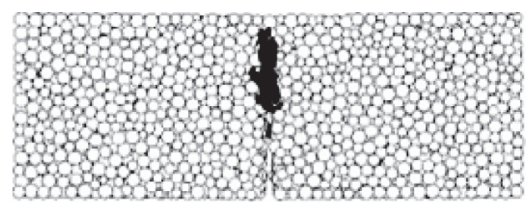

(c)

FIGURE 12: Microcracks distribution in SC3PB specimen (A1). (a) Crack initiation. (b) Crack growth. (c) Specimen failure.

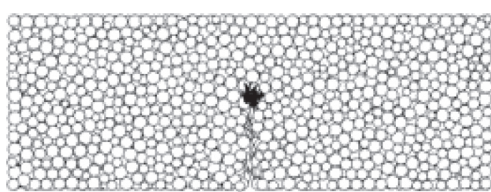

(a)

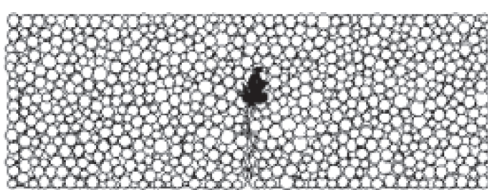

(b)

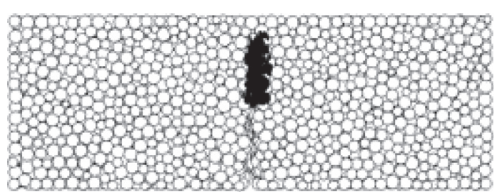

(c)

FIGURE 13: Microcracks distribution in SC3PB specimen (B1). (a) Crack initiation. (b) Crack growth. (c) Specimen failure.

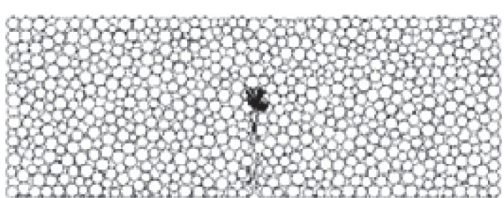

(a)

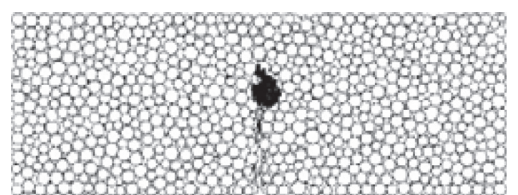

(b)

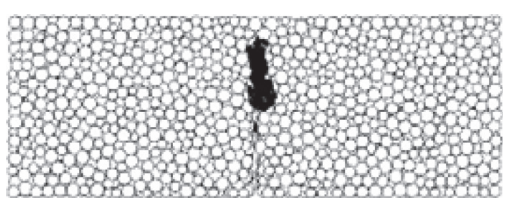

(c)

FIGURE 14: Microcracks distribution in SC3PB specimen (C1). (a) Crack initiation. (b) Crack growth. (c) Sample failure.

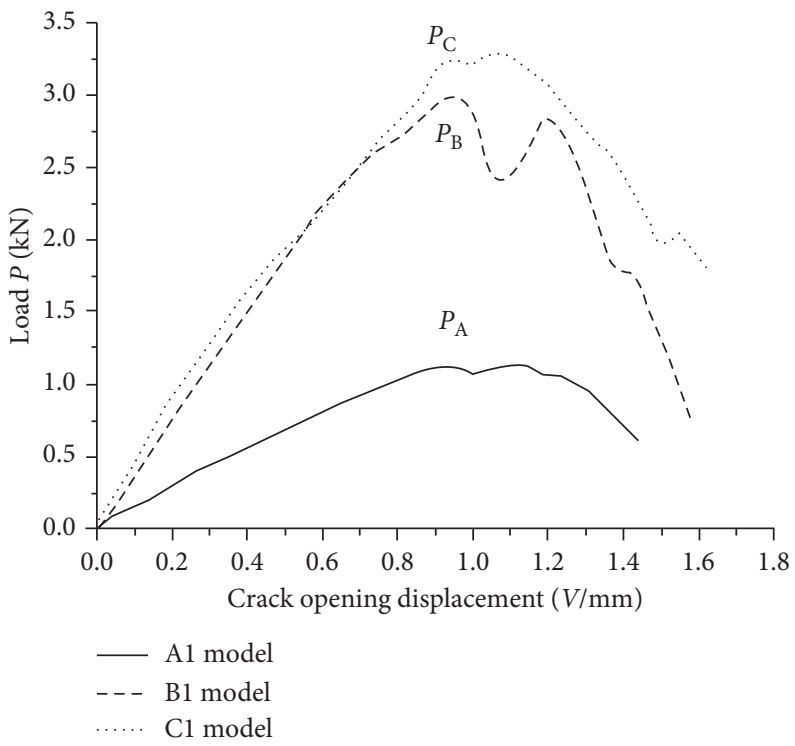

Figure 15: $P-V$ curve of the three-point bending test. 


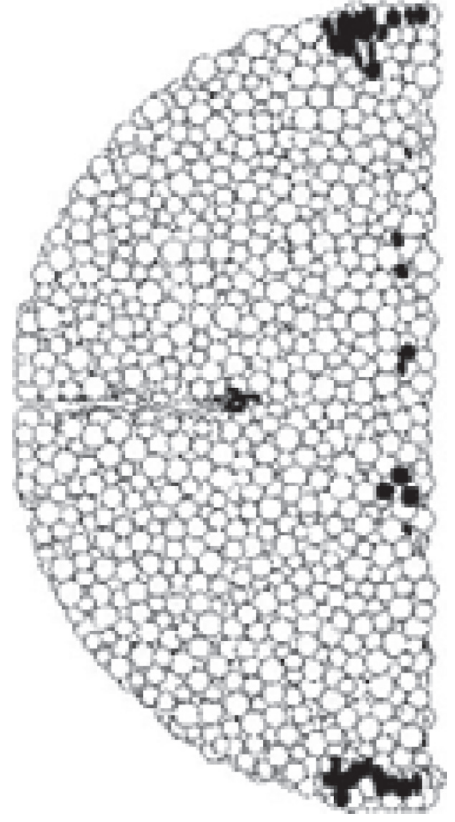

(a)

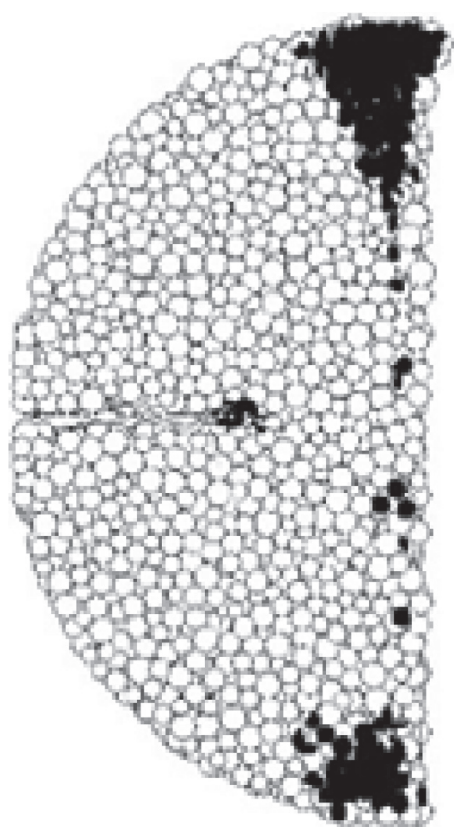

(b)

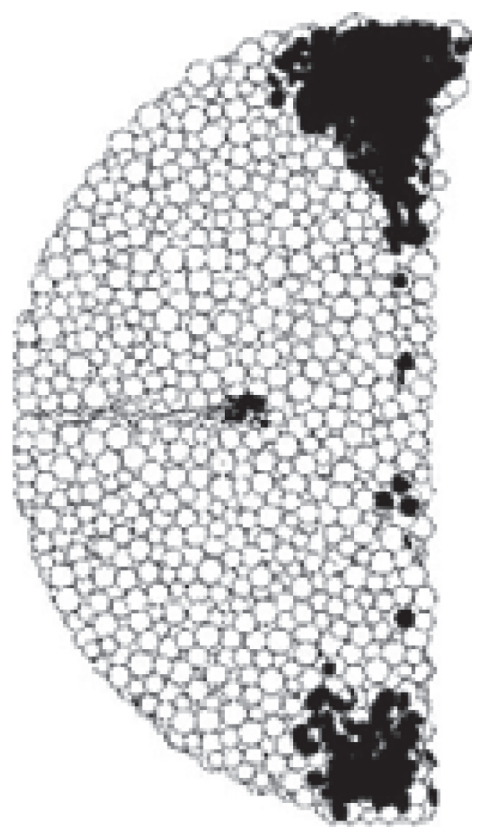

(c)

FIgURE 16: Microcracks distribution in ECFSD specimen (A2). (a) Crack initiation. (b) Crack growth. (c) Sample failure.

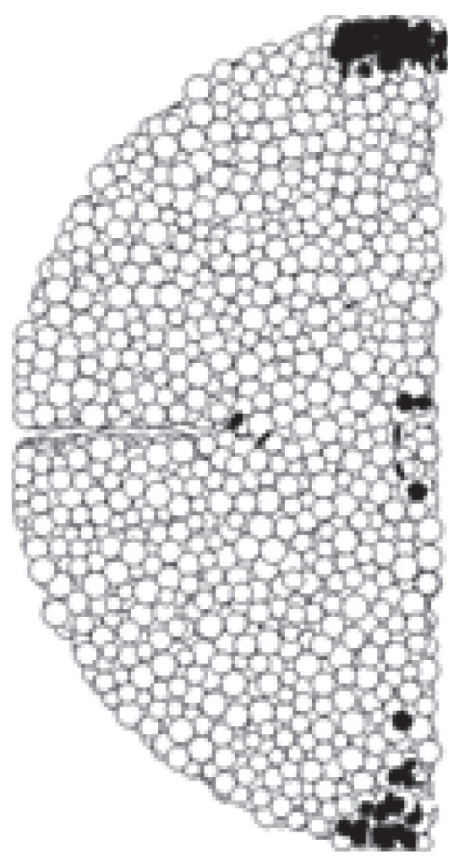

(a)

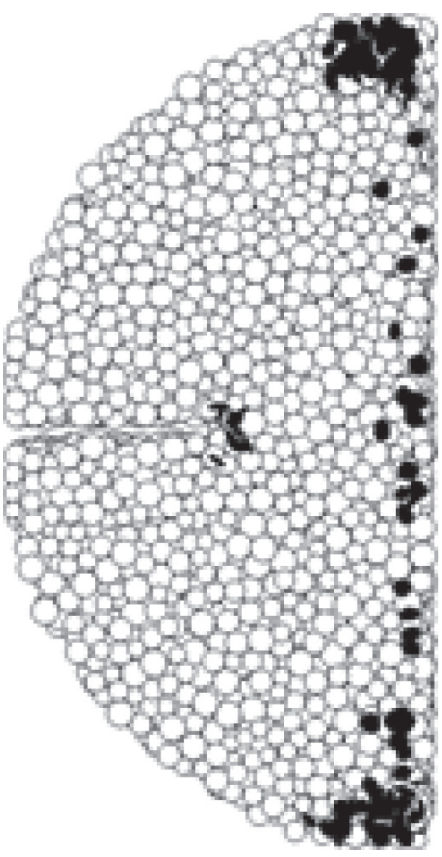

(b)

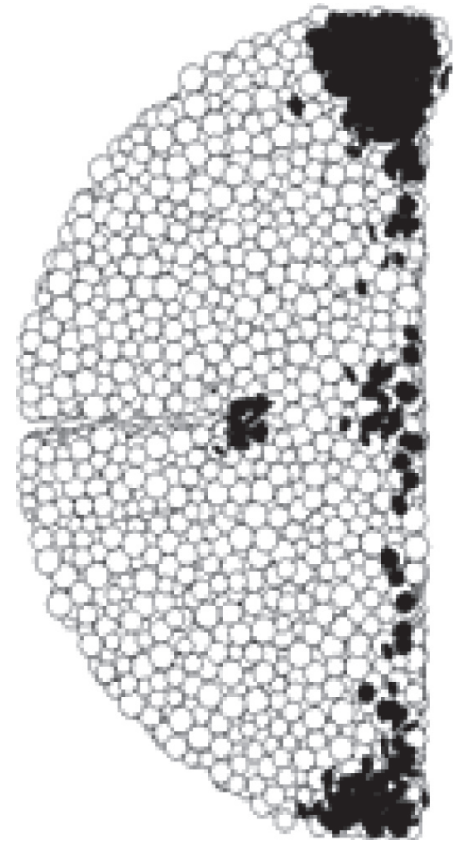

(c)

Figure 17: Microcracks distribution in ECFSD specimen (B2). (a) Crack initiation. (b) Crack growth. (c) Sample failure.

propagation stage of the prefabricated crack. At this time, the specimen is not completely damaged. As the loading continues, the load curve increases, and the second peak value may exceed the first.
3.3. CCNBD Test Results. The distribution of microcracks in the models is shown in Figures $20-22$. It is found that microcracks occur at the loading points of the sample and the end of precut groove firstly, then the precut groove begins to propagate, and the microcracks run through the sample along the diameter direction finally. A number of 


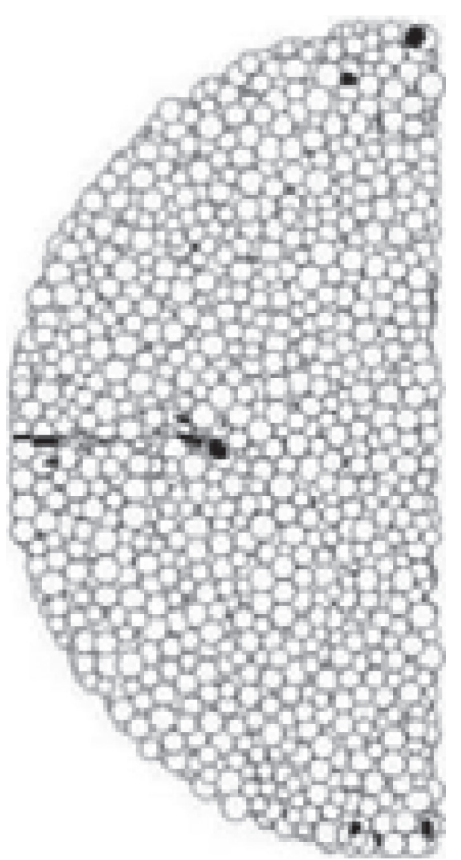

(a)

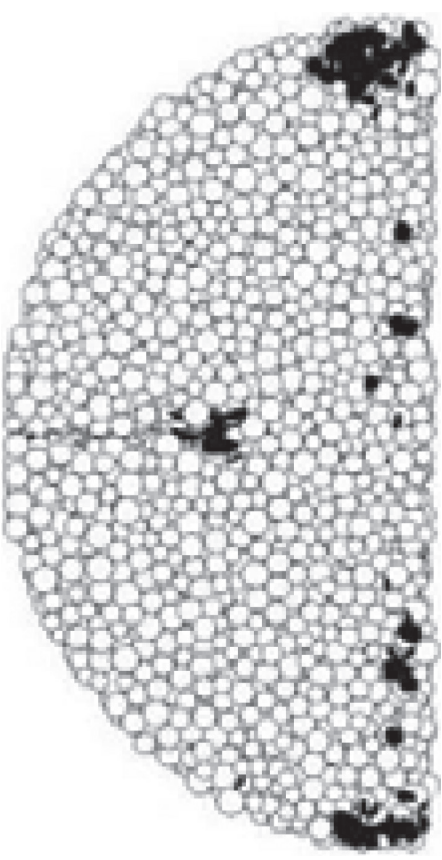

(b)

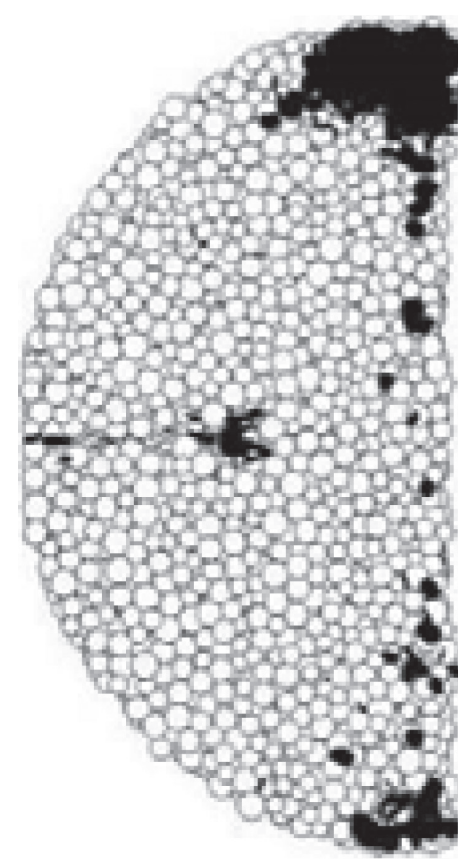

(c)

FIGURE 18: Microcracks distribution in ECFSD specimen (C2). (a) Crack initiation. (b) Crack growth. (c) Sample failure.

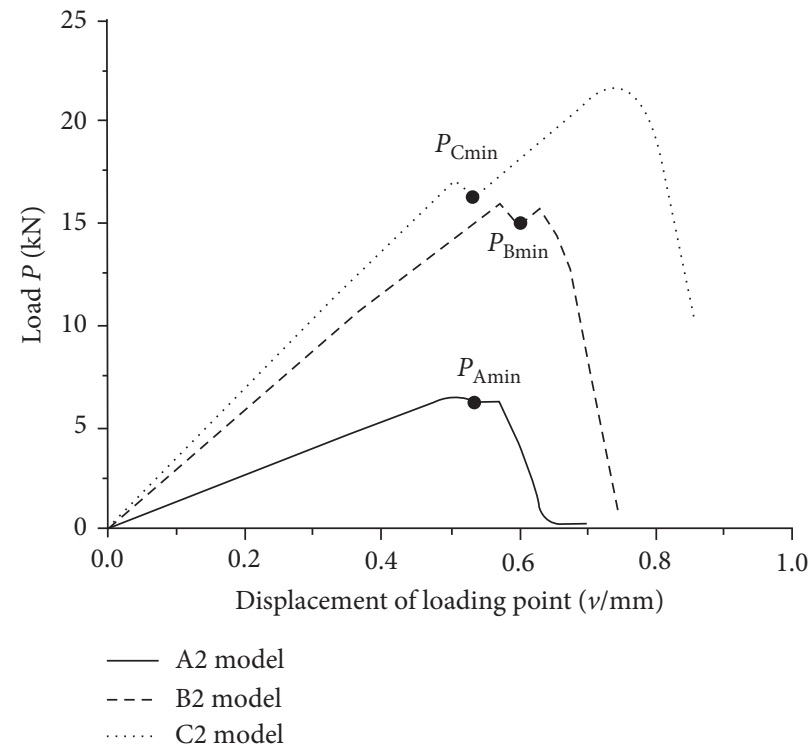

FIgURe 19: $P$ - $v$ curve of the ECFSD test.

microcracks near the loading platform occur because of the local fracture caused by the stress concentration.

The curve of load $P$-displacement $v$ is recorded in the test (as shown in Figure 23), and the maximum load in the test is substituted into formulas (3)-(6), for calculation.

According to the test results, $P_{\text {Amax }}=12.2 \mathrm{kN}$, $P_{\mathrm{Bmax}}=18.4 \mathrm{kN}, P_{\mathrm{Cmax}}=20.4 \mathrm{kN}$; then, $K_{\mathrm{IC}}$ of models are calculated. The results show that $K_{\mathrm{IC}}=1.13 \mathrm{MPa} \cdot \mathrm{m}^{1 / 2}$ for A3 model, $K_{\mathrm{IC}}=2.55 \mathrm{MPa} \cdot \mathrm{m}^{1 / 2}$ for $\mathrm{B} 3$ model, and $K_{\mathrm{IC}}=2.83 \mathrm{MPa} \cdot \mathrm{m}^{1 / 2}$ for $\mathrm{C} 3$ model.

3.4. ECFR Test Results. The distribution of microcracks in the model is shown in Figures 24-26. In the process of loading, the vertical microcracks are produced on the inner wall of the samples firstly; then, the cracks propagate 


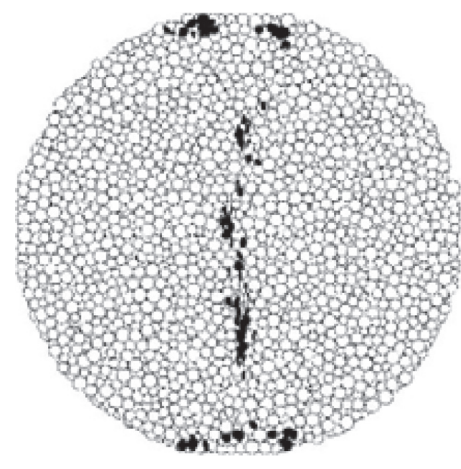

(a)

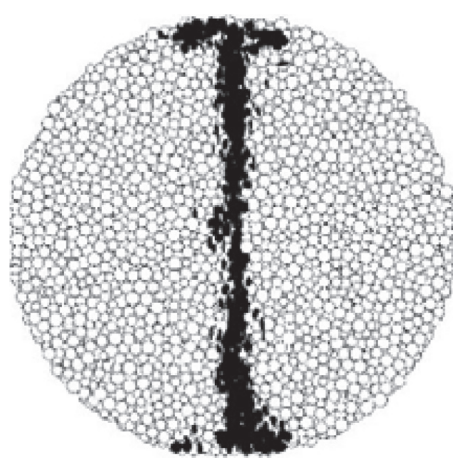

(b)

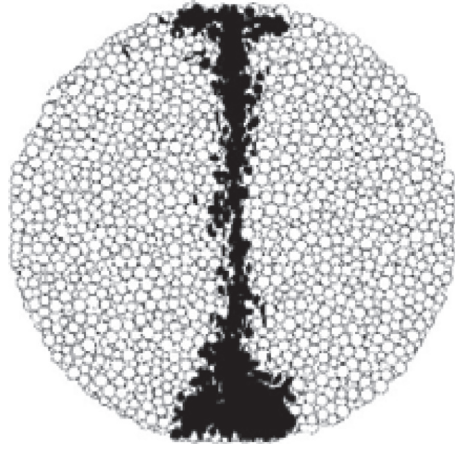

(c)

FIGURE 20: Microcracks distribution in CCNBD specimen (A3). (a) Crack initiation. (b) Crack growth. (c) Sample failure.

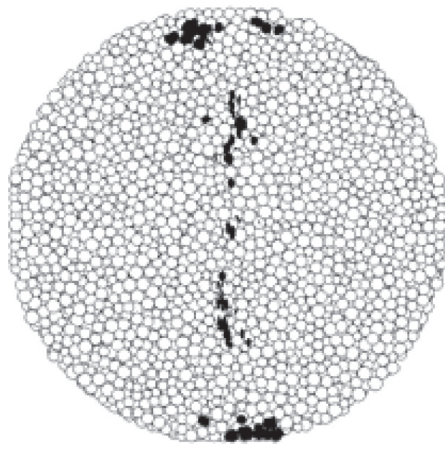

(a)

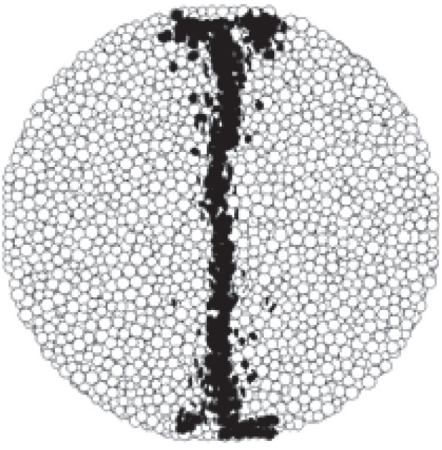

(b)

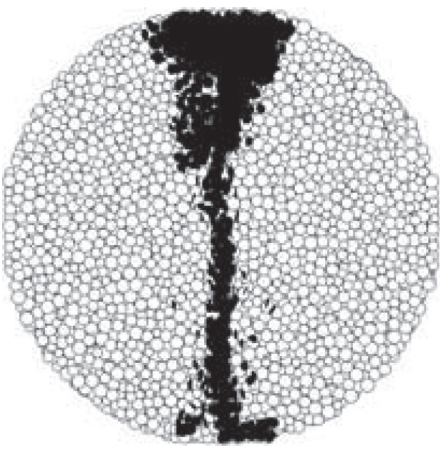

(c)

FIgure 21: Microcracks distribution in CCNBD specimen (B3). (a) Crack initiation. (b) Crack growth. (c) Sample failure.

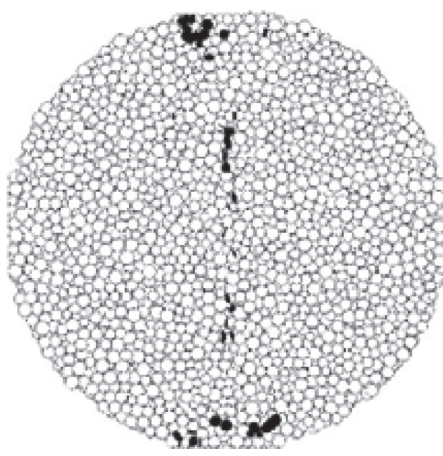

(a)

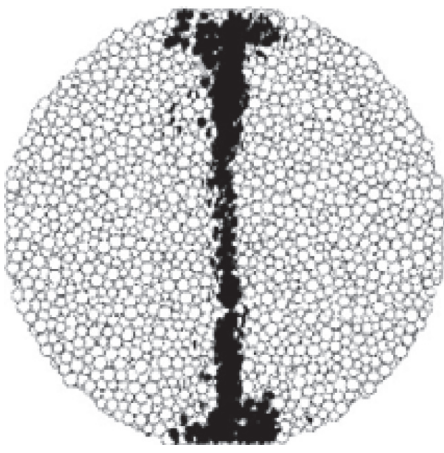

(b)

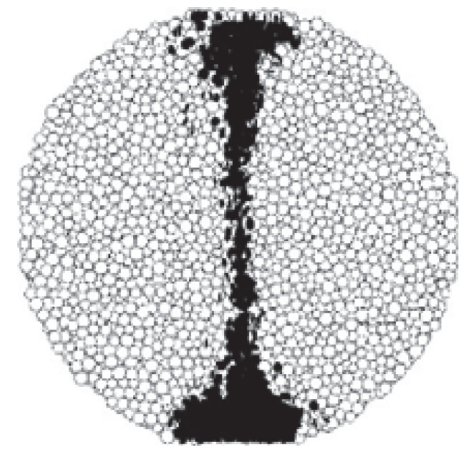

(c)

FIGURE 22: Microcracks distribution in CCNBD specimen (C3). (a) Crack initiation. (b) Crack growth. (c) Sample failure.

gradually from the inside to the outside along the loading direction and run through the samples. At the same time, the precut cracks also propagate to the inside of the samples. Tensile failure also occurs in the right half of the ring.

The curve of load $P$-displacement $v$ is shown in Figure 27. According to reference [17], the local minimum load $P_{\min }$ is substituted into formula (7), where $Y_{\max }=1.0468$, $P_{\mathrm{Amin}}=5.71 \mathrm{kN}, P_{\mathrm{Bmin}}=13.0 \mathrm{kN}, P_{\mathrm{Cmin}}=15.2 \mathrm{kN}$, and the results are as follows: $K_{\mathrm{IC}}=1.00 \mathrm{MPa} \cdot \mathrm{m}^{1 / 2}$ for $\mathrm{A} 4$ model, $K_{\mathrm{IC}}=2.27 \mathrm{MPa} \cdot \mathrm{m}^{1 / 2}$ for B4 model, and $K_{\mathrm{IC}}=2.65 \mathrm{MPa} \cdot \mathrm{m}^{1 / 2}$ for C4 model.

\section{Analysis of Test Results}

In each group of samples, SC3PB and CCNBD samples are damaged by the propagation of precut cracks, while ECFSD 


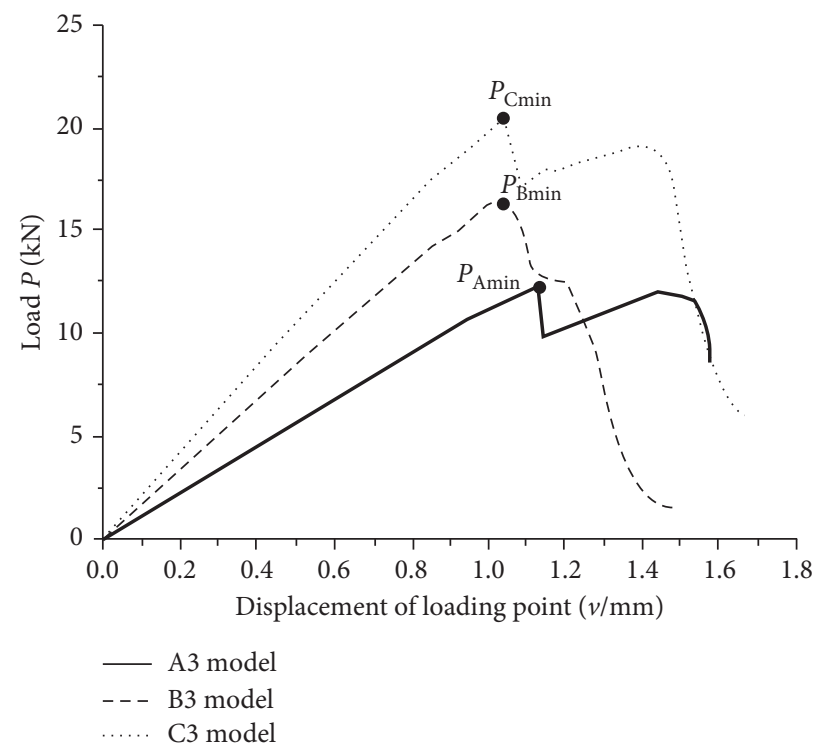

Figure 23: $P-v$ curve of the CCNBD test.

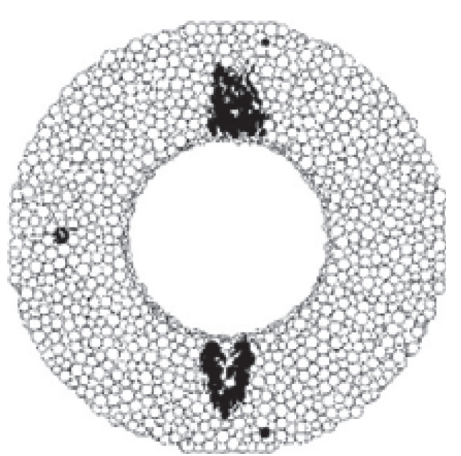

(a)

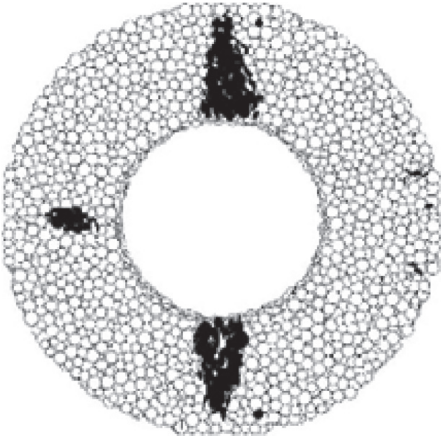

(b)

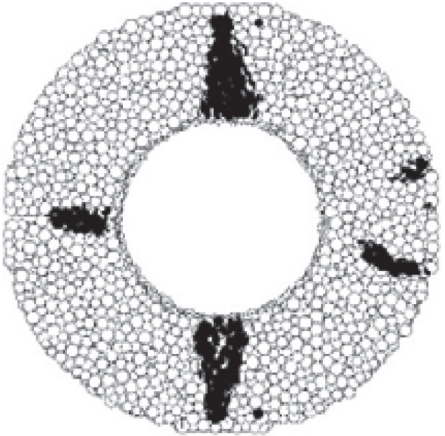

(c)

FIgURE 24: Microcracks distribution in ECFR specimen (A4). (a) Crack initiation. (b) Crack growth. (c) Sample failure.

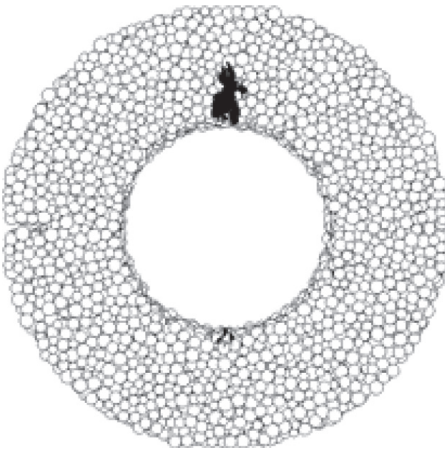

(a)

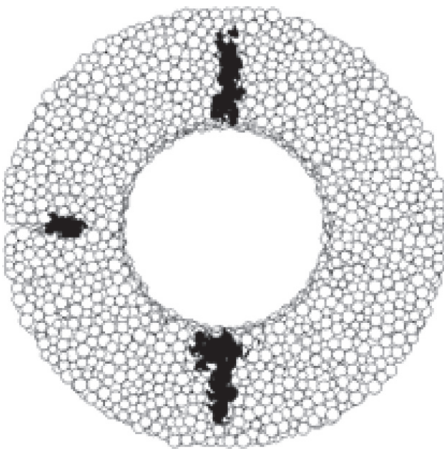

(b)

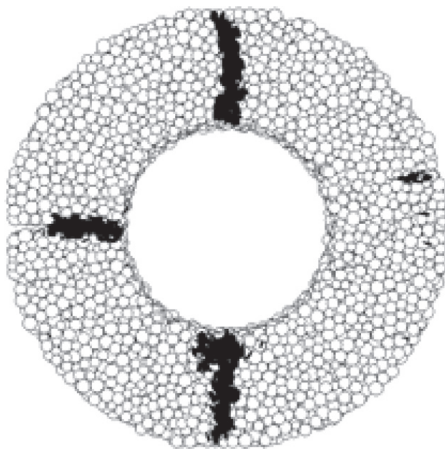

(c)

FIgURE 25: Microcracks distribution in ECFR specimen (B4). (a) Crack initiation. (b) Crack growth. (c) Sample failure.

and ECFR samples are damaged by not only the propagation of precut cracks, but also the coalescence of vertical cracks. The load-displacement curve of each specimen will decrease slightly and then increase again, which is caused by stress release after crack initiation. By comparing the fracture toughness of each model (see Table 5), it can be found that, 


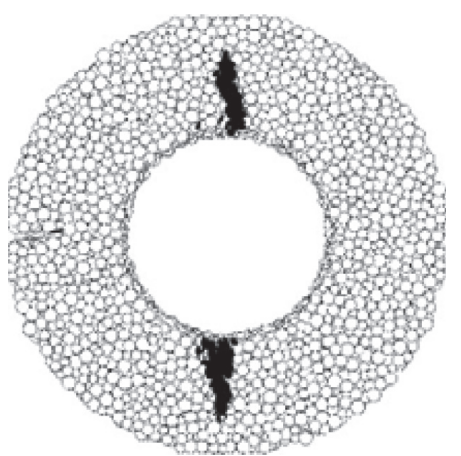

(a)

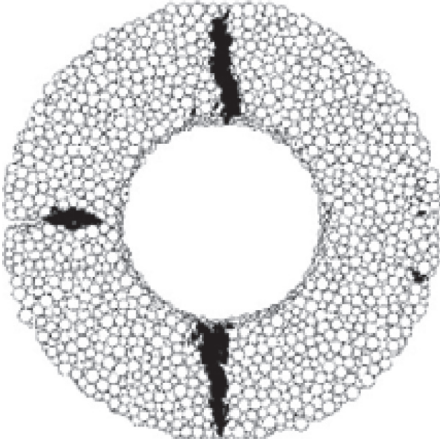

(b)

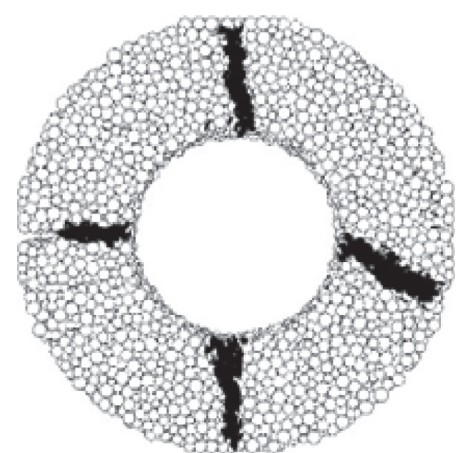

(c)

Figure 26: Microcracks distribution in ECFR specimen (C4). (a) Crack initiation. (b) Crack growth. (c) Sample failure.

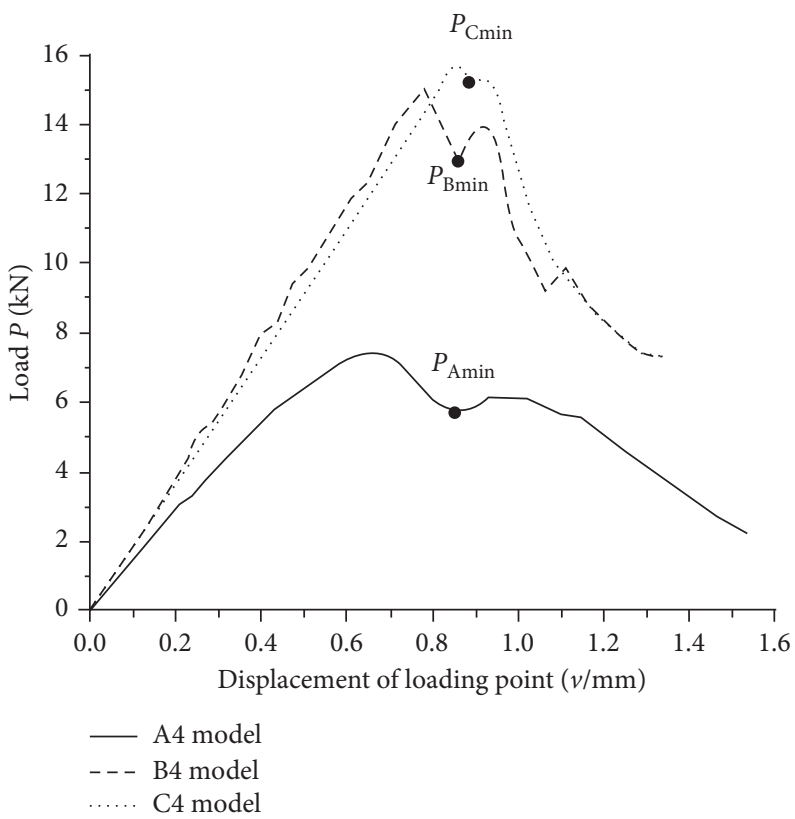

FIgURe 27: $P-v$ curve of the ECFR test.

in group $\mathrm{A}$, the difference between the four sample types is $0.21 \mathrm{MPa} \cdot \mathrm{m}^{1 / 2}$. In group $\mathrm{B}$, the difference between the four sample types is $0.39 \mathrm{MPa} \cdot \mathrm{m}^{1 / 2}$. In group $\mathrm{C}$, the difference between the four sample types is $0.26 \mathrm{MPa} \cdot \mathrm{m}^{1 / 2}$. On the whole, the fracture toughness of the ECFR samples is smaller than that of the ECFSD and CCNBD samples (Tables 4 and 5).

By comparing the distribution of microcracks in each model, it can be found that, in ECFSD and CCNBD samples, both the crack growth and the fracture of the loading point can be obtained. The short crack propagation distance in the ECFSD specimen is not the main reason for specimen failure. It is because the crack tip is within the width covered by specimen loading platform as precut crack propagating. In the contact diagram (as shown in Figure 28), the black line represents the pressure between particles, and the thickness of the line represents the magnitude of force. It is explicit that the specimen is compressed along the vertical direction, and the precut crack tip will not undergo tensile failure anymore, so the crack will not further expand. Under a lower loading rate, there are fewer microcracks outside the propagation path in the CCNBD specimen, which makes the results relatively accurate.

The ECFR specimen can be regarded as a platform Brazilian disk specimen with edge crack and central circular hole. Compared with the disk or half-disk specimen, the ring-like specimen is more prone to compression deformation.

The calculated results are closely related to the ratio of internal and external radius $r / R$, the ratio of crack length to external diameter $a / R$, and other geometric parameters. There are many microcracks outside the crack propagation path, which has a certain influence on the test results. 
TABLE 5: Test results of fracture toughness $\left(\mathrm{MPa} \cdot \mathrm{m}^{1 / 2}\right)$.

\begin{tabular}{lcccc}
\hline & SC3PB sample & ECFSD sample & CCNBD sample & ECFR sample \\
\hline A model & 0.92 & 1.11 & 1.13 & 1.00 \\
B model & 2.49 & 2.66 & 2.55 & 2.27 \\
C model & 2.72 & 2.91 & 2.83 & 2.65 \\
\hline
\end{tabular}

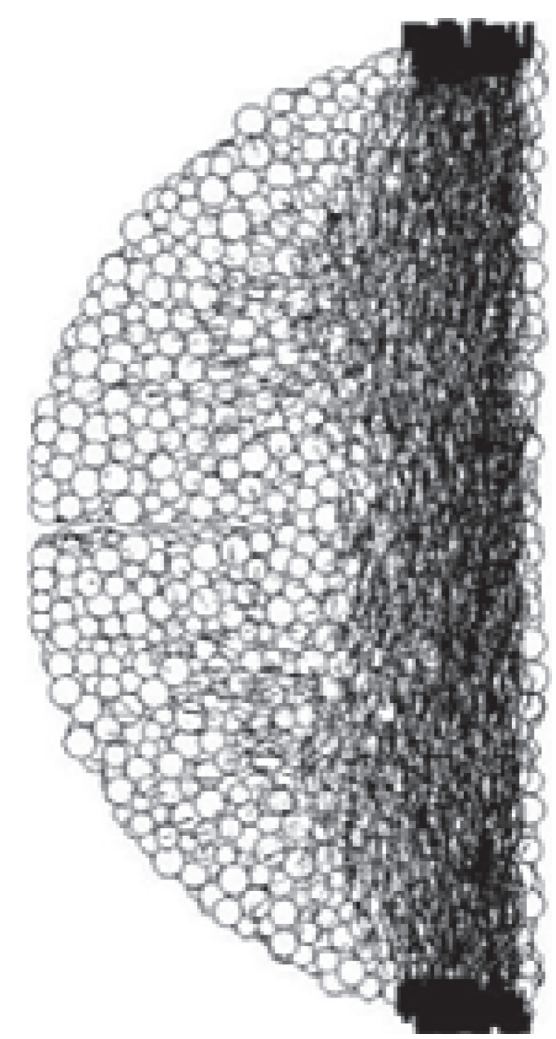

FIgURE 28: Contact force between particles in the ECFSD model.

\section{Conclusions}

The fracture toughness test of rock with 4 types of specimens is researched by the numerical simulation method of particle flow. The failure forms and load-displacement curves are analyzed and compared. The conclusions in this research are listed as follows:

(1) The results of the numerical test are reasonable and effective. The maximum difference between the test results of different samples with the same strength parameter is $0.39 \mathrm{MPa} \cdot \mathrm{m}^{1 / 2}$.

(2) When the loading rate is reduced to $0.01 \mathrm{~m} / \mathrm{s}$, the effect of loading rate on fracture toughness can be reduced to less than $0.1 \mathrm{MPa} \cdot \mathrm{m}^{1 / 2}$. So, the loading rate of $0.01 \mathrm{~m} / \mathrm{s}$ is reasonable.

(3) During the loading process, the microcracks occur in multiple areas in ECFR specimens. The test results of ECFR specimens are $6 \%-11 \%$ smaller than those of CCNBD specimens. For ECFSD specimens, there are many microcracks generated along the loading direction as the propagation of prefabricated crack. The test load is larger than the other specimens, so the fracture toughness of ECFSD specimens is $0.08-0.11 \mathrm{MPa} \cdot \mathrm{m}^{1 / 2}$ larger than that of CCNBD specimens.

(4) The SC3PB and CCNBD specimens are spilt along the loading direction because of the propagation of prefabricated crack, and the test results of SC3PB are 0.06-0.21 MPa.m ${ }^{1 / 2}$ less than those of CCNBD specimens.

\section{Data Availability}

The article data used to support the findings of this study are included within the article.

\section{Conflicts of Interest}

The authors declare that there are no conflicts of interest regarding the publication of this paper.

\section{Acknowledgments}

This work was supported by the Natural Science Foundation of the Jiangsu Higher Education Institutions of China (Grant 
nos. 19KJD410001 and 18KJB440002), the Science and Technology Project of Housing and Construction in Jiangsu Province (Grant No. 2018ZD199), and the Science and Technology Project of Changzhou (Grant No. CJ20190020).

\section{References}

[1] J. A. Franklin, Z. Sun, and B. K. Atkinson, "Suggested methods for determining the fracture toughness of rock," International Journal of Rock Mechanics and Mining Science \& Geomechanics Abstract, vol. 25, no. 2, pp. 71-96, 1988.

[2] S. Zhang and Q. Z. Wang, "Determination of rock fracture toughness by split test using five types of disc specimens," Rock and Soil Mechanics, vol. 30, no. 1, pp. 12-18, 2009.

[3] Z. D. Cui, D. A. Liu, G. M. An, and M. Zhou, "Research progress in model I fracture toughness testing methods for rocks," Journal of Test and Measurement Technology, vol. 23, no. 3, pp. 189-196, 2009.

[4] J. Wei, W. C. Zhu, R. F. Li, L. L. Niu, and Q. Y. Wang, "Experiment of the tensile strength and fracture toughness of rock using notched three point bending test," Journal of Water Resources and Architectural Engineering, vol. 14, no. 3, pp. 128-132, 2016.

[5] M. R. Ayatollahi and J. Akbardoost, "Size and geometry effects on rock fracture toughness: mode I fracture," Rock Mechanics and Rock Engineering, vol. 47, no. 2, pp. 677-687, 2014.

[6] J. J. Meng, P. Cao, K. Zhang, and P. Tan, "Brazil split test of flattened disk and rock tensile strength using particle flow code," Journal of Central South University(Science and Technology), vol. 44, no. 6, pp. 2449-2454, 2013.

[7] S. Q. Yang, Y. H. Huang, and X. R. Liu, "Particle flow analysis on tensile strength and crack coalescence behavior of brittle rock containing two pre-existing fissures," Journal of China University of Mining and Technology, vol. 43, no. 2, pp. 220-226, 2014.

[8] Y. H. Huang and S. Q. Yang, "Particle flow simulation on marco- and meso-mechanical behavior of red sandstone containing two pre-existing non-coplanar fissures," Chinese Journal of Rock Mechanics and Engineering, vol. 33, no. 8, pp. 1644-1653, 2014.

[9] Y. H. Huang and S. Q. Yang, "Particle flow simulation on fracture characteristics and crack propagation mechanism of holed-cracked Brazilian disc specimen," Rock and Soil Mechanics, vol. 35, no. 8, pp. 2269-2277, 2014.

[10] L. N. Y. Wong and X.-P. Zhang, "Size effects on cracking behavior of flaw-containing specimens under compressive loading," Rock Mechanics and Rock Engineering, vol. 47, no. 5, pp. 1921-1930, 2014.

[11] K. Peng, J. Zhou, Q. Zou, and F. Yan, "Deformation characteristics of sandstones during cyclic loading and unloading with varying lower limits of stress under different confining pressures," International Journal of Fatigue, vol. 127, no. 10, pp. 82-100, 2019.

[12] K. Peng, Z. Liu, Q. Zou, Q. Wu, and J. Zhou, "Mechanical property of granite from different buried depths under uniaxial compression and dynamic impact: an energy-based investigation," Powder Technology, vol. 362, pp. 729-744, 2020.

[13] K. Peng, H. Lv, F. Z. Yan, Q. L. Zou, X. Song, and Z. P. Liu, "Effects of temperature on mechanical properties of granite under different fracture modes," Engineering Fracture Mechanics, vol. 226, p. 106, 2019.

[14] K. Peng, Y. Wang, Q. Zou, Z. Liu, and J. Mou, "Effect of crack angles on energy characteristics of sandstones under a complex stress path," Engineering Fracture Mechanics, vol. 218, p. 106, 2019.

[15] Y. Wang, X. Shang, and K. Peng, "Relocating mining microseismic earthquakes in a $3-\mathrm{D}$ velocity model using a windowed cross-correlation technique," IEEE Access, vol. 8, pp. 37866-37878, 2020.

[16] X. Y. Shang and H. Tkalčić, "Point-Source inversion of small and moderate earthquakes from $\mathrm{P}$-wave polarities and $\mathrm{P} / \mathrm{S}$ amplitude ratios within a hierarchical bayesian framework: implications for the geysers earthquakes," Journal of Geophysical Research: Solid Earth, vol. 125, no. 2, 2020.

[17] Z.-D. Cui, D.-A. Liu, G.-M. An, B. Sun, M. Zhou, and F. Q. Cao, "A comparison of two ISRM suggested chevron notched specimens for testing mode-I rock fracture toughness," International Journal of Rock Mechanics and Mining Sciences, vol. 47, no. 5, pp. 871-876, 2010.

[18] Z. D. Cui, D. A. Liu, G. M. An, M. Zhou, and Z. Q. Li, "Research for determining mode I rock fracture toughness $K_{\mathrm{IC}}$ using cracked chevron notched Brazilian disc specimen," Rock and Soil Mechanics, vol. 31, no. 9, pp. 2743-2748, 2010.

[19] J. F. Guan, G. S. Qian, W. F. Bai, X. H. Yao, and J. W. Fu, "Method for predicting fracture and determining true material parameters of rock," Chinese Journal of Rock Mechanics and Engineering, vol. 37, no. 5, pp. 1146-1160, 2018.

[20] B. Bahrami, M. R. Ayatollahi, A. M. Mirzaei, and M. Y. Yahya, "Support type influence on rock fracture toughness measurement using semi-circular bending specimen," Rock Mechanics and Rock Engineering, vol. 53, no. 5, 2019.

[21] N. Wong, T. Guo, and W. Lam, Experimental Study on Two Semi-circular Bending Methods for Mode I Fracture Toughness Determination in Tuff, pp. 17-20, Seattle, Washington, DC, USA, 2018.

[22] D. Huang and X. Q. Li, "Numerical simulation research on characteristic strength of marble based on development of microcrack," Rock and Soil Mechanics, vol. 38, no. 1, pp. 253-262, 2017.

[23] Y. L. Zhao, W. Wan, W. J. Wang, and P. C. Zhao, "Compressive-shear rheological fracture of rock-like cracks and subcritical crack propagation test and fracture mechanism," Chinese Journal of Geotechnical Engineering, vol. 34, no. 6, pp. 1050-1059, 2012.

[24] C. G. Zhang, Y. Zhou, J. R. Yang, and Q. Z. Wang, “A serious of edge cracked flattened ring (disc) specimens for determining fracture toughness: numerical analysis and calibration results," Chinese Journal of Rock Mechanics and Engineering, vol. 33, no. 8, pp. 1546-1555, 2014.

[25] D. O. Potyondy and P. A. Cundall, "A bonded-particle model for rock," International Journal of Rock Mechanics and Mining Sciences, vol. 41, no. 8, pp. 1329-1364, 2004.

[26] M. J. Jiang, H. Chen, and F. Liu, "A microscopic bond model for rock and preliminary study of numerical simulation method by distinct element method," Chinese Journal of Rock Mechanics and Engineering, vol. 32, no. 1, pp. 15-23, 2013.

[27] Q. Z. He and Z. N. Li, Engineering Fracture Mechanics, Beijing University of Aeronautics and Astronautics Press, Beijing, China, 1993.

[28] L. Z. Wu, X. M. Jia, and Q. Z. Wang, "A new stress intensity factor formula of cracked chevron notched Brazilian disc (CCNBD) and its application to analyzing size effect," Rock and Soil Mechanics, vol. 25, no. 2, pp. 233-237, 2004. 